\section{FEDERAÇÃO E PARLAMENTARISMO DA COMPATIBILIDADE DO SISTEMA PARLAMENTAR GOVERNO COM A FORMA FEDERATIVA DE ESTADO}

\section{Paulo Brossard de Souza Pinto}

\author{
Não é fácil contestar concretamente \\ a uma objeção em si mesma tão im \\ precisa.
}

Hamilton, The Federalist, LXV.

1 - A apresentação do projeto de emenda n. da República, com o objetivo de implantar da n. 4, à Constituição em nosso país, assim na União, comantar o govêrno de gabinete Congresso, na imprensa, em nos Estados, suscitou debate.

Entre os opoentes do juridicos, fecund enumeram-se os que apontam projeto de emenda constitucional brasileiro um impedimentom na organização federativa do Estado tido como um valor universal sistema proposto, impedimento ora corrência do nosso direito positivo. irremovível, ora tomado como deAs duas posições direito positivo.

cial ou acidental, atribuída aos têrmáu de inconciliabilidade, essenmo, merecem tratamento distinto.

\section{2 - A controvérsia não é nova entre nós.} zação das praxes parlamentares da República, opondo-se à legaliplicáveis sob a Federacão (1) do antigo regime, inculcava-as ina-

Alís, nos debatesção (1).

Aliás, nos debates da Constituinte, foi mais ou menos corrente
proclamar-se não se afinar

(1) História Constitucional da República, 2.a ed., 1894, I. 142. ma de Estado $\left({ }^{2}\right)$, embora a propaganda republicana se fizesse conjugada à da federação, e sem embargos ao sistema parlamentar, "cujas imperfeições inspiravam os ataques ao "poder pessoal" do Imperador $(3)$.

Pouco mais tarde, em 1896, registrava Assis Brasil: "para os presidencialistas, é absolutamente incompreensível govêrno parlamentar em república federativa; para os outros, não sòmente é a coisa mais natural, como deve mesmo ser mais profícuo o sistema parlamentar, sendo a república federativa, do que se fôr unitária" $\left.{ }^{4}\right)$.

Depois caberia a Ruy Barbosa, na plataforma civilista, referirse ao debate. Indicados os conceitos insuscetíveis de reforma, naquela ocasião, ponderava o insigne jurista: "adotadas estas precauções tranqüilizadoras, contra as demasias de espírito de reforma, poderia ela encetar-se, como convém, no terreno das nossas instituições constitucionais, moderada, gradual e progressivamente. Essas reservas afastariam especialmente das primeiras tentativas reformatórias a questão entre a república parlamentar e a presidencial. Não é pouco numerosa a corrente que contra esta já se pronuncia. Mas eu ainda "não me animaria a segui-la. Não duvido que em breves anos se venha a impor a sua discussão. Mas abrir com ela o primeiro ensaio de reforma constitucional, seria expô-la, quase com certeza, ao malôgro, em tớpicos a respeito dos quais é exequíível, por açodamento em relação a um problema ainda não maduro, contra o qual as exi"gências da ortodoxia republicana são até agora irredutíveis" ( $\left.{ }^{5}\right)$.

Mas a esta exposição, formulada em têrmos políticos, acrescentou Ruy, após referência aos dois regimes: "o que eu não saberia é de que modo conciliar com êste (o govêrno de gabinete) o mecanismo do sistema federal", embora, posteriormente, tivesse reformado, neste passo, o seu pensamento $\left({ }^{6}\right)$.

A par dessa corrente, sempre houve outra que preconizava a instituição do parlamentarismo, sem prejuízo da autonomia dos Estados e das franquias locais.

$$
\text { *** } *
$$

(2) Agenor de Roure - A Constituinte Republicana, 1920, I 346. (2) Agenor. de Roure - A Onstituinte Republicana, 1920, I, 346.
(3) Américo Brasiliense Os programas dos partidos, Manifesto . Republicano.
Paulo Brossard de Souza Pinto Prosidencialismo o Parlamentarismo na ideologia de Rui Barbosa. Separata da Revista da Fraculdade de Direito de Pôrto Alegre, I, n. ${ }^{\circ} \mathbf{1}_{1}$ pgs. 6 , ssis Brasil - Unidade Nacional, conferência, 1883; Do Govêrno Presidencial. 3." ed, Assis Brasil 1934 , pg. 118

Amaro Cavalcanti - Regime Federativo, 393.
Prudente de Morais, in Discursos Parlamentares de J. Nabuco, ed. da Oâmara dos Deputados, 1950 Morais,

(5) Assis Brasil - Do Govêrno Presidencial, 119. pgss. 25 e 26 .
(6) Paulo Brossard de Souza Pinto - Presidencialismo e parlamentarismo n*
radeologia de Ruy Barbosa, 44 pgs. 
3 - E' a maneira de prover o executivo dos Estados e a duração nárquica ou republicańcio dêle, que definem a forma de govêrno, mode relação entre êles parlamentar (8). F a residencial, diretorial on mia desfrutada pelos órgãos das unidadolítica, geradora da autonolização meramente administrativa, unidades federadas, ou a descentrafederativo ou existência do Esta

$V$ isto é, porti

político, porque refletem, cada qua de govérno, de Estado e o sistena ções próprias e finalidades peculiar, aspectos distintos, com motivahostilizam, antes da, mediante combinacões em cada unidade politicamente constituí-

Daí o Estado exercer explicáveis à luz da. História dos povos.

tes verticais, pelos poderes sua competência, distribuindo-a em corvêzes, mediante bros e até os Municípios (10).

forma de Estado, e Bélgica podem ser unitárias, quanto a a Itália e a França. Mas, enquanto de gabinete. Do mesmo modo cas, as últimas têm a forma primeiras são monárqui-

Repúblicas a forma republicana de govêrno.

Unidos. A Alemanha sistema parlamentar, em contria também o foram, que adotaram o retoral da federac̃o em contraste ao presidencial daqueles, e o.di-

$\mathrm{E}$ enquanto

o rei inglês, representado por a Austrália têm como chefe de Estado

(7) Ruy - O art. $6.0^{\circ}$ da Constituição, pg. 65

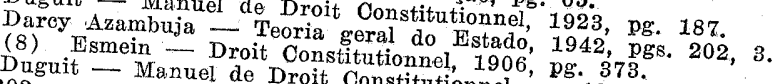

Redslob - Le régime parlementair Dg. 196. Legons de Droit Public, 1926 Burdeau - Manuel de Droit Constitution, pg. 1.

Bonnar- Teoria General del Estado, 1934, 1947, pg. 100

Nézard - riléments de Droit Public, 1946, pggs. 55 e 58.

Laferrière - Manuel de Droit Constitut6, pgs. 124 e segs.

(9) - Manuel de Droit Constitutionnel, 1949, 1947, pgs. 753

(9) Darcy Azambuja - op. cit., cap XXIII

Ruy Cirne Limas - Direito Constitucional, 1942, pg. 105

Roger Pinto - Droit Constitutionnel, 1948, prinistrativo, 1939, § 15

(11) Couve de Miranda - Comentários à Constituigão de 1946, I, 152

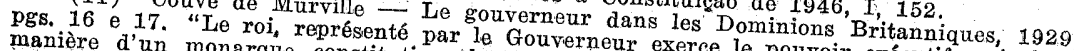

manière d'un monarque constitutionnel, Gouverneur exerce le pouvoir exécutifi mais 1929 ministres responsables devant l'assemblée locale. Qu

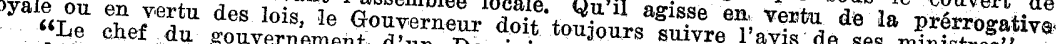
Grande-Bretagne, d'Irlande et des Dominionion est le Roi, qui est à la mis cois "Roi". me la Couronne ne peut y exercer es ar "Roi do ou plusieurs représentants suivant l'importance de Dominion'" (pong. elle ies délègue à àn. federativamente, como a Alemanha, antes de Weimar, que era mo. nárquica e federativa (12), se distinguem desta, possuidora, ao tempo de um govêrno pessoal e polìticamente irresponsável $\left({ }^{13}\right)$, porque seregem mediante gabinetes responsáveis.

Não há, destarte, uma relação existencial entre regime político. $\epsilon$ forma de Estado.

Como foi enunciado, o sistema de govêrno, porque deriva do modo da divisão dos poderes, se prende ao relacionamento e a limitações impostas pela lei ou aceitas pelo costume, dos poderes legislativo e executivo, enquanto a federação decorre da descentralização política, da repartição de competências entre a União e os Estadosmembros, discriminadas e garantidas pela Constituição federal, sob cujo império êstes se auto-constituem e governam, participando ainda na formação dos órgãos de govêrno nacional ${ }^{14}$ ).

\section{***}

4 - O regime parlamentar é uma modalidade da democracia representativa. Repousa sôbre a igualdade dos poderes políticos, cuja colaboração é reciprocamente garantida pélos meios de que cada um dispõe para obrigar o outro. O gabinete. "la pièce essentielle do la machine politique", na frase de Duguit (15), constitui o ponto de convergência dos poderes legislativo e executivo e sela a harmonia. dêles.

Participa a um tempo do legislativo, de que é expressão, donde emana a sua existência e no qual tem assento, no mínimo, o seu presidente, tendo"o cahmado, por isso, o clássico Bagehot, "uma comissão do parlamento", e do executivo, de que, na expressão de Berthélemy, é a "parte móvel", e que o integra juntamente com o chefe do Estado, polìticamente irresponsável $\left.{ }^{16}\right)$.

A responsabilidade política do gabinete perante os representantes do povo, que votam o apoio ou a censura ao govêrno colegiado ou a um membro dêle, é contrabalançada pela responsabilidade política do parlamento, dissolúvel por decreto do chefe do Estado, referendado, como todos os outros, pelo gabinete.

São recursos destinados a compor a harmonia dos poderes políticos, que se visualiza no conselho de Ministros.

Taband - Le Droit Public de l'tmpire Allemand 1900, Is \& 7.0 pess, 105 egs., e \& $90^{\circ}, \mathrm{pgs}$. 157,8 .

Ruy O Direito do Amazonas ao Acre Setentrional, 1910, I, pg. 92.

(13) Laband - op. cit., I, \& 24, pgs. 318 e segs. e \& 26, pgs. 343 e 348 a 351.

1938. pgs. 67 e 68 .

Olimpio Ferraz de Oarvalho - Sistema Parlamentar, 1933, pgs. 61. e segs.

14) Frederic Austin Ogg - English Government and Politics, 1947, pgs. 74 e 76

15) Duguit - op. cit. pg. 196.

Bagehot - La Constitution Anglaise, trad. Gaulhiac, 1869, pg. 14 
Regime político que reflete, no plano prático, uma modalidade unitários, como em federativos poderes, tanto é aplicável em Estados como nas estaduais. Indica o regime

técnica mais ou menos felizentar um mecanismo de govêrno, uma pressupostos desta (17).

$$
* * *
$$

5 - A estrutura federativa do Estado deriva de outras origens se condiciona até ao seu dado espacial

Enquanto do sistema parlamentar

ticá-lo diferentes povos que atinjam é lícito concluir possam prajá seria arbitrário predizer que quam certo nível cultural e político, tivamente, ainda se esmere qualquer Estado se organizará federalisonjeiras instituicões. Assim a sua população em cultivar as mais zação e rico localismôes. Assim, embora conheçam larga descentralicilmente se federalizarão Por extensão tendem a princípio, os países de grande presidencial ou parlamentar, indes, enquanto que o regime político, da menor ou maior evolucã independe dêsse fator, derivando ambos

$E^{\prime}$ que o Estado fuço do regime representativo $\left({ }^{18}\right)$. com base territorial (19).

suem, como a União, ferativa está em que os Estados-membros posCódigo Supremo, e uma competência peculiar, pré-traçada pelo daí a faculdade de auto-orcício dela não sofrem reparos, decorrendo autonomia é corolário da competên e auto-govêrno. O gôzo de uma trativa e judiciária. tederal. Judiciaria, imodificável por arbítrio da entidade política

Do exposto não dissente o insigne Kelsen: "el Estado Federal representa un aumento de grado de la descentralización: tenemos retipo cuando no sólo la ejecución y la lescentralización: tenemos este tidas entre una autoridad central y varias autoriontran reparcuando, además, se confiere a los ór varias autoridades locales, sino tencia para darse la modo total o bien solamente parcial, es decir, dentro del marco fijado por las normas establecidas en la constitución central" $\left({ }^{20}\right)$.

E Darcy Azambuja, com a segurança habitual das suas lições, após balançar as teorias à respeito, conclui: "a faculdade de autoorganização e de auto-govêrno, é um dos traços fundamentais do regime federativo. Êste princípio é necessário, porém não bastante. Devem também as coletividades federadas concorrer para a forma"ção da vontade federal, participar na organização dos órgãos centrais federativos" $\left({ }^{21}\right)$.

Um constitucionalista de' nota, João Mangabeira, escrevia, ao sustentar o anteprojeto constitucional do Itamaratí: "o que caracteriza o Estado Federal é a sua coexistência com Estados constitucionalmente autônomos, dentro das raias que a Constituição Federal lhes traça, e a impossibilidade de modificação desta por lei ordinária da Assembléia Nacional, e sem que êles sejam ouvidos. Esta é a fórmula compatível com a realidade do mundo moderno, nas suas instituições atuais" $\left({ }^{22}\right)$.

Ora, a distribuição de competências, assim legislativas, como de administração e judicial, que pressupõe, por sua vez, as constituições estaduais, ao mesmo tempo que a federal, exige apenas a pluralidade de entidades políticas, independendo dos seus sistemas de govêrno.

Êstes valem como instrumentos, aptos ou inadequados, de realização das tarefas atribuídas pelas Constituiçôes, nacional ou esta- duais, aos círculos e entidades integrantes da federação.

6 - Ora, se numa federação presidencial, disserta Raul Pilla, "tem cada Estado o seu parlamento e o seu govêrno próprios, por que não os poderá ter também com o sistema parlamentar? Será a circunstância de ser, aqui, o poder executivo responsável perante o legislativo? Evidente é que não, porque cada govêrno, federal ou estadual, é exclusivamente responsável perante o respectivo parlamento, federal ou estadual, conforme o caso. Assim, se a União tem - seu parlamento e o seu gabinete perante êle responsável, nada, absolutamente nada impede que os Estados-membros também tenham o seu parlamento e o seu gabinete igualmente responsável. Como na federação presidencial, na parlamentar também tudo é questão de delimitação de competência entre o Estado federal e os Estados fe"derados. Exatamente as mesmas dificuldades num e noutro caso" $\left.{ }^{23}\right)$.

(20) Keisen - Compêndio de Teoria General del Estado, trad. de Recaséns Siches $\begin{aligned} & \mathrm{X} \\ & \text { cf. Azcaráte, } 1934 \text {, peoria General del 180. }\end{aligned}$ (21) Darcy Azambuja 0 op. cit., pg. 302 .

Laband - op. eit., I, \& $7^{\circ}$, pgs.

Jean Dabin - op. eit., pg. 330 .

Frederic Austin Ogg - op cira cit. pôns da Constituição, 1934, pg. 61.

Frederic Austin Ogg - op. cit. pgs. 74 e 75

in "Dírio de Notíciaș", de Pôrto Alegre, em 22-I-46. 
Em verdade, o direito comparado oferece exemplos sugestivos. da conjugação num mesmo Estado, do parlamentarismo e dafederacial.

são dêles através dar a teoria da separação de poderes e da divisem lobrigar qualquer regras de competência, Gettell conclui assim, mas de Estado, derivados da govêrno e as forreferidos: "it should be noted aplicação de um e outro dos princípios the basis of functional noted that the classification of governments on is a cross classification. The functional presidential and cabinet types, reappears in each of the territorial separation of departments the central governme territorial subdivisions. In a unitary state of the presidential type, created by the constitution, may be either the cabinet type, as in Great certain Latin-American states, or of visions in a unitary in Great Britain and France. The local subdivernment creates for them or have whichever type the central gostate the central government permits them to create. In a federal either of the presidential type created by the constitution, may be cabinet type, as in Canadape, as in the United States, or of the may adopt whe subdivisions of the federal state trictions in the national type they prefer, unless there are legal ressubdivisions of federal constitution which prevent. In practice, the in the same form that obtain have set up the presidential Thus the states in the American union provinces have adopted the of government, while the Canadian

Com efeito, cabinet system". ( ${ }^{24}$ ).

dentes da tese exposta. Estudando e a trália são dois exemplos concluque produziu uma "obra monum as instituições do primeiro, Bryce, americanas, (25) escre as instituições nortewell contaken as a whole, the institutions approved in Britain. in the main, such as long experience as the Parliamentary system to has made the first attempt to apply Africa have followed machinery has worked

E depois:

$$
\text { "The Canadia }
$$

Constitution to the British ral and not a unitary government a new country in which a Fedevariations, certain which experience features of the United States Federal system (n) defects. that experience had disclosed. It followed in other points the parliamentary and Cabinet system of Britain; and - what was no less important - it carried over into Canada the habits and tradition by which that parliamentary system had thriven" $\left({ }^{26}\right)$

O clássico Dicey, já em fins do século passado, esclarecia: "Si nous considérons le caractère fédéral de la Constitution du Dominion, mous devons inévitablement la regarder comme une copie, - mais non pas une copie servile - de la Constitution des États-Unis. D'autre part; la Constitution canadienne est étudiée exclusivement, dans cet ouvrage, en tant que gouvernement fédéral. Je maintiens donc comme correcte mon affirmation, que le gouvernement du Dominion est modelé sur celui de l'Union. Au contraire, si nous comparons l'exécutif canadien à l'exécutif américain, nous nous apercevons tout de suite que le gouvernment canadien est copié sur le système du gouvernement parlementaire de Cabinet, tel qu'il existe en Angleterre, et n'imite en aucune façon le gouvernement présidentiel de l’Amérique" (27).

No mesmo sentido, Couve de Murville, estudando a figura do Governador nos Domínios britânicos, salientou quanto convinha para desfazer dúvida sôbre a conciliação do sistema parlamentar do govêrno com a organização federativa de Estado.

"Dans les Dominions", esclarece o autor citado, "de même qu'au Royaume-Uni, le pouvoir exécutif est directement responsable devant le Parlement, émanation de la volonté populaire".

E noutro passo, comparando regime des Dominions com o da Inglaterra: "Leurs institutions politiques fonctionnent aussi normalement que celles du Royaume-Uni..."

E mais adiante: "c'est de l'Angleterre que les Dominions se rapprochent de plus en plus, quant à la pratique même du régime parlementaire. Le gouverneur, comme le Roi, ne fait que se conformer aux avis de ses Ministres, et en même temps la responsabilité politique de ceux-ci devant le Parlement est definitivement établie" ( ${ }^{28}$ ).

Bryce, dissertando sôbre o Canadá, não é menos positivo: "the frame of the Dominion or National Government has been constructed on the lines of the Cabinet or Parliamentary system of Britain and

(26) James Bryce - Modern Democraties - 1927, I, 497 e 506, 7. James Bryce - The American Commonwealth. Lrancesa, La République "Le gouvernement fédéral ou du. Dominion est formé sur le type du "système du "Cabinet" anglais. Is ministère à sa place au Parlement, et conserve ses pouvoirs selon Ia volonté de la Chambre des Communes. Le Governeur général est dans la situation terre, asissant sur les conseils de ministres responsables. Il peut dissoudre le Parlement. Dans chachune des provinces, il $\mathrm{y}$ a un Ministère responsable fouctionnant d'aprés le système du Cabinet anglais, le Lieutenant-Gouverneur représentant la couronne et (27) A Dicer - Introduction a l'étude du Droit Constitutionnel, trad. A. Batut et $G$. Jèze, 1902, pg. 147, nota 1. Wade and Godfrey Phillips, Constitutional Lạ, 4. ${ }^{a}$ ed., 1950 , pg. 418. 
all her self-governing colonies. Executive power is vested nominally is in fact exercised byeral as representative of the British Crown; but only so long as they can retain the group of Ministers, who hold office minion House of Commons. They support of a majority in the Doment, and in it all of creature of the House of Commons, Thus the actual Executive is the power, that of appealing to the people byssing as against it only one If ministers do not dissolve people by a dissolution of Parliament. and the election goes against them must resign, and if they dissolve

Cabinet is formed" $\left({ }^{29}\right)$.$$
\text { E, ao tratar da }
$$

the Governor-General, astrália; "Executive power resides nominally in in the Cabinet of high officials who form British Crown, but virtually be members of the Legislature who form his Ministry, and who must port of a majority in the

Por sua vez, in the House of Commons" $\left({ }^{30}\right)$.

federadas do Canadá, Ernest Cheveriação dos poderes nas Províncias vince a une législatur, Linest Chevegrin expõe que: "... chaque proassemblée unique. Le lieute à l'exception de Québec, est composé d'une verneur pour une durée illimitée, maverneur est nommé par le goucinq années d'appointements té par un conseil exécutif ou sauf pour cause determinés; il est assistements ministériels, lequels sabinet, comprenant les chefs des déparre" ${ }^{31}$ ).

which correspond to "they (the Governments of the Nine Provinces, in the U. S. A.) reproduce the in the Australian Commonwealth and Government provided for the system of Cabinet and Parliamentary ture, that of the British Parliaminion. ... The system is, in miniaelected by universal suffrage for four and Cabient. The Legislature is lution by the Cabinet" (32)

A federaç̃o aus

sim na órbita nacional, como nas estaduais é parlamentares, aspelo erudito prefaciador como nas estaduais, é igualmente descrita Delpech e Laferrière ( ${ }^{33}$ ) Neste particy

tutions of the six States, all of course o estudo de Bryce: "the Constiof of the Commonwealth,

(30) Bryce - op. par J. Delpech et Laverrin, in "Les Constitutions modernes", par in cit., pg. 420.

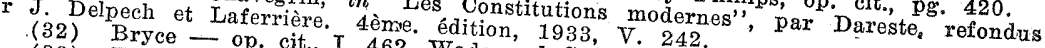
(33) Ernest Chavegrin - loc. Wade and God frey Phillips, op. cit., pg. 418 , 1966 a 202 . Wade
420. are reproductions of the British frame of government. ... Each State has a Governor appointed by the Crown (usually for five years), and a Cabinet selected from members of the Legislature by the persons whom the Governor summons to form an administration, such person being usually the leader of the party which at the moment constitutes the majority of the Assembly" ${ }^{(34)}$.

$$
\text { *** }
$$

7 - Tenho assim como demonstrado à luz da doutrina e da prática constitucional dos povos, a improcedência da apontada antinor mia entre govêrno de gabinete e Estado Federal.

\section{***}

8 - Não faltaram juízos, entretanto, que, embora admitissem. a conciliabilidade do parlamentarismo com a federação, encontravam insuperável obstáculo em expresso dispositivo da lei magna brasileira.

O prof. Sampaio Dória entendia inconstitucional o projeto de emenda n. 4, à vista do $\S 60^{\circ}$ do art. 217 do Código Supremo, pelo qual "não serão admitidos como objeto de deliberação projetos tendentes a abolir a Federação e a República". E sustentava ser a fundamental característica da federação brasileira a "igualdade de representação dos Estados no Senado e a igualdade de competência entre os dois ramos legislativos, salvo os casos específicos, que a Constituição enumera", acrescentando que "o sistema parlamentar importa em abolir a eqüivalência de poderes gerais entre o Senado e a Câmara: importa em anular a representação igual dos Estados no Senado, para o exercício de poderes eqüivalentes aos da Câmara dos Deputados". A conclusão era terminante: "logo, qualquer projeto de índole parlamentar é inconstitucional, não pode sequer ser objeto de deliberação do Congresso" $\left.{ }^{(35}\right)$.

Sem discutir o alcance do dispositivo constitucional, bastaria considerar que, pela adoção do govêrno de gabinete não se buliria na

(34) Bryce - op. cit. 176.7. A pg. 193, prossegue o mesmo autor: "booth in the Commonwealth and in the seceral States the Executive Government consistis of 8 of the administrative deparments. Though there may often be found a "Minister withouts portfolio". These form the Cabinet. All have seats in one or other house of the Legislature, and are supposed to represent the best political capacitiy of the party for the time being in the majority. The place of Prime Minister is, according to British.
usage, taken by the statesman who has been commissioned by the Governor to form usage, taken by the

Sôbre a evoluẹ̃a do parlamentarismo e da federação no Canadá e na Austrá. lia, v. L. Lowell, Le gouvernement de l'Angleterre, trad. par A. Nerinex, 1910, chap. Donal St. Clair Gainer. A Monarquia Britânica, in Rev. For. OXXX, 16 a 21 e Sear Désy. A vida constitucional do Canadá, Rev. For., CIII, 23 a 29 Presidencialismo", in " 0 João de Oliveira F.o - "Incompatibilidade do Parlamentarismo com a Federacão", in "Joânal do Comércio", Rio, 16-X-49 e Rev. For. OXXVII, 583. 
sigual representação no dos Estados, nem êstes passariam a ter deos dois racentação no Senado, e a similitude de atribuicóes desos específicos, que a Constituic̃a não sofreria reparo, "salvo os catentes e que ao professor da hicano enumera", mesmo agora exisescaparam. Ao seu númor da histórica Faculdade de S. Paulo não mara, se sòmente perante se acresceria mais um, em favor da Câgabinete.

Se Câmara e Senado, em regra, têm a mesma competência não mente atribuiçóes específica das casas do Congresso, possui igualmente atribuições específicas, claramente determinadas pela Consti-
tuição.

À Câmara dos Deputados, privativamente, compere procedência ou improcedência da acusac̃̃onte, compete declarar a República e contra os Ministros acusação contra o Presidente da os daquele, e ainda dêles, nada poderia fazer sem $59, \mathrm{I}$ ). E

contra êle a Câmara exclusivamente, caberia julgá-los, nada podendo vesse esta cabais razốes para declarandesse de absolvê-los, ainda ti-

De resto, decretada para declarar-lhes a culpabilidade. suas funções até ao julgamento ação. ficam os acusados suspensos das

Destarte, ainda no atual regime pode. (art. 88, parágrafo único) te, é certo, afastar os governantes pode a Câmara, temporàriamenprerrogativa: a responovernantes do poder. Compreende-se, aliás, a mentar, evolveu da responsabilidáde pen, peculiar ao sistema parlapresentativa, com a qual náo deixa penal da antiga monarquia residencialismo $\left({ }^{36}\right)$.

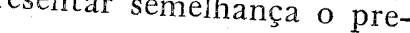

da tomada de, compete, outrossim, de modo privativo, a iniciativa

Por sua vez, o Senado tente da República. (art. 59, II).

Além de julgar o Presidente tem igualmente atribuições exclusivas. bilidade e os Ministros de Estado nos da nos crimes de responsacom os daquele, perante o Senado nos da mesma natureza conexos qualquer participação to Senado são processados e julgados sem

(36) Esmein - op cit 119

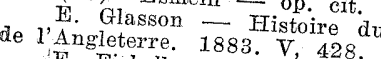

tituions politique civiles e judicioire Kelsen - Teoria Constitution d'Angleterre, trad. Ch. Vogel, 1864, II, 409, 410

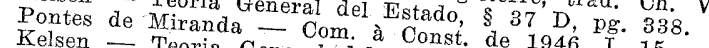

zico, 1950.317 . Teoria General del Derecho y del mstado, trad. de Garcia Maynez,

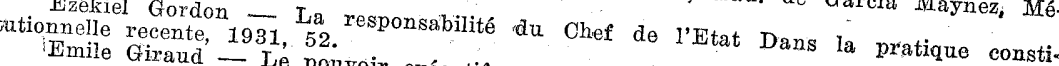

Emile Giraud - Le pouvoir exécutif - $67,68,392$. nal Federal e o Procurador-Geral da República, também nos crimes de responsabilidade. (art. 62, I e II).

E ainda ao Senado, exclusivamente, cabe aprovar a escolha de certos magistrados, do Procurador-Geral da República, dos Ministros do Tribunal de Contas, do Prefeito do Distrito Federal, dos Membros do Conselho Nacional de Economia e dos chefes de missão diplomática de caráter permanente. (art. 63, I).

Sòmente ao Senado, com total independência do outro ramo do poder legislativo, compete autorizar os empréstimos externos dos Es"tados, do Distrito Federal e dos Municípios. (art. 63, II).

E' ainda incumbência sua, peculiaríssima, suspender a execução de lei ou decreto declarados inconstitucionais por decisão definitiva do Supremo Tribunal. (art. 64).

Cabe à Câmara dos Deputados, por sua vez, em relação à Câmaa Alta, a iniciativa da lei de fixação das fôrças armadas e a de tôdas as leis sôbre matéria financeira. (art. $67 \$ 10^{\circ}$ ).

Visto é, portanto, não ser idêntica a competência de uma e outra casa do Congresso mesmo no atual regime.

Da confiança da Câmara, segundo o projeto de emenda constitucional n. 4, dependeria o Conselho de Ministros, e, por via de conseqüência, sòmente ela seria dissolúvel.

Incluir-se-iam essas peculiaridades, portanto, nos "casos específicos que a Constituição enumera".

E nem por isso se teria abolido "a eqüivalência de poderes gerais entre o Senado e a Câmara", nem importaria "em anular a representação igual dos Estados no Senado".

A conclusão do prof. Sampaio Dória, segundo a qual "qualquer projeto de índole parlamentar é inconstitucional”, é manifestamente infundada.

De resto, a restrição constitucional é no sentido de vedar o curso de projetos tendentes a abolir a Federação e a República.

A restrição, sem discutir a sua valia teórica e prática, segundo cânon de hermenêutica, deve ser interpretada estritamente.

E abolir, registra-o Morais, é suprimir, extinguir, aniquilar, anular, cassar. Ao lado do velho dicionarista, Laudelino Freire esclarece: abolir, revogar, anular, extinguir, suprimir, pôr fora de uso. E Pereira e Souza, no clássico Dicionário Jurídico: "he por uma cousa fora de uso".

Augusto Magne, no seu Léxico, especialmente dos períodos medieval e clássico, confirma: "abolir, anular, revogar, extinguir, pôr em total desuso, com referência, principalmente, a lei e costumes". E como sinônimos apresenta - revogar e derrogar.

17 - R D - 20 Vol. 


$$
-714-
$$

Com efeito, a reforma proposta atinge o sistema de govêrno qual independe da forma de Estado. A aprovac̃a restabeleceria a monarquia, nem faria

9 - As mesmas razões o prof faria unitária a República.

a tese esposada peló Instituto Solatan Grande do Sul, no Congresso dos Aidvogados do Rio de 1949 . Direito Constitucional da Bahia

E em conferência que pronunciou na ínclita Faculdade de reito daquele Estado, novamente dissertou sôbre a controvérsiạ, re gabinete? Perante a Câmajeções: "perante que Câmara responde o rante o Congresso em sessõ̃es dos Deputados? Perante o Senado? Peseparadas, cada um sessóes conjuntas? Ou, ainda, perante as duas

"Se perante a Câmar vez, como na elaboração das leis? anula, extinguindo-se a federação "Se o gabinet

te representado na Câmara perante o Senado, o povo, diretamenvêrno do país.

"Se perante

penderia sempre o Congresso em sessões conjuntas, o fiel da balança Senado. elaboração daste as duas Câmaras, cada uma por sua vez, como na liberaçôes nem sempre concordes nas discussões em duplicata, e dedas Câmaras

Não obstante

federação, não são idênticas conferência, de novo reconhecia que "na O que a caracteriza, é a eqüivalênciaições da Câmara e do Senado. mas prerrogativas, sem embargo de alguSenado". Aliás

Estado, uma Câma Kelsen, sem prejuízo do caráter federativo do o Senado "sólo cámara popular" (38) un veto suspensivo contra los acuerdos de la

E isto sem considerar a opinião radical de João Mangabeira que do federal $\left.{ }^{39}\right)$.

Como se ve

argumentos em ampastre professor de São Paulo não ofereceu novos o notavel certame jurí

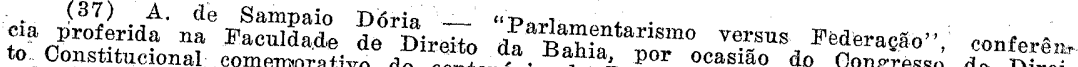

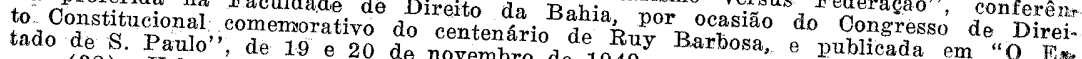

(38) Kelsen - de 19 e 20 de novembro de 1949

(39) João Mangabeira - op. cit., 52 . dico não aderiu a elas $\left({ }^{40}\right)$, como, aliás, já as rejeitara o Instituto da Ordem dos Advogados do Rio Grande do Sul ( ${ }^{41}$.

10 - Outro jurista eminente a impugnar a conciliabilidade do parlamentarismo com a federação, foi o deputado Afonso Arinos, hoje professor de Direito Constitucional da Faculdade de Direito da Universidade do Brasil, - como relator da Comissão Especial que opinou sôbre o projeto de emenda n. 4.

O ilustre constitucionalista começa por discordar do prof. Sampaio Dória, reconhecendo que só projetos que abolissem e não apenas modificassem a federação, seriam vedados pela lei fundamental, afir mando, outrossim, que se o projeto amesquinha as funções legislativas (sic) do Senado, "esta circunstância, por si só, não aboliria a Federação no Brasil" ( ${ }^{42}$ ).

Passando a estudar os Estados federais que praticam (ou praticaram) o govêrno parlamentar, aponta o Canadá, a Alemanha e a Áustria, para classificá-los sob o rótulo de federalismo europeu, em contraste ao americano, porque naqueles países as unidades federadas desigualmente se representam (ou representavam) no Senado.

Em face da federação australiana reconhece que ela está mais próxima do nosso tipo americano, mas, pelo fato de serem os governadores estaduais nomeados pelo rei inglês $\left({ }^{43}\right)$, desconsidera aquela manifestação histórica de Estado federal onde se pratica o regime parlamentar.

E por êste fato assimila a situação dos Estados australianos à das províncias brasileiras ao tempo do Império, porque também os seus presidentes eram de nomeação do poder centra!. afirmando: "esta perda de capacidade de eleger o chefe titular do govêrno local é uma conseqüência lógica do parlamentarismo monárquico, como acontecia no Brasil-Império" ( $\left.{ }^{44}\right)$.

Aqui o reparo se impõe de pronto. Sendo o Brasil um Estado unitário até 89 , as suas provincias não gozavam de autonomia política. O govêrno delas era mero reflexo do central. $\mathrm{E}$ ao contrário

(40) Revista Forense, CXXVIII, 16 (nota).

da emenda parlamentarista', Separata (42) Afonso Arinos - Parecer sôbre a emenda parlamentarista, avulso da Câ-

mara dos Deputados, pg. 30 . Estados da Austrália é de nomeacáa real, enquanto o das
(43) o governador dos Esto da províncias canadenses é nomeado pelo governador-geral. Couve, de Hau, "op. cit. 15 Bstados, ao contrário do que se verifica no Canadá, Gettell, op. cit. 228 e Bryce, op. cit., II, ${ }_{(44)}^{176}$ Afonso Arinos - Parecer cit. 34 


$$
-716-
$$

dêste, o govêrno provincial nem era colegiado, nem responsável, nem
parlamentar.

ara do Império, na sustentando um projeto de federação zia que Império, na década de maior desenvolvimentoração na Câ nomia que uma das razóes por que as províncias nimento do regime, dicentral a impossibilidade de fazer de uma desitavam de autocontral, como são as presidências de provína delegação do govêrno mente responsável perante aquêles que aíncia, um govêrno efetivaêles" ( $\left.{ }^{45}\right)$.

Mas convém ainda nom mo o governador do Commotar que os governadores dos Estados, inglês, representam um papel semelhan australiano, nomeado pelo rei "reinam" e não governam, taref ao dêste na Grã-Bretanha tes $\left(^{46}\right)$, não haven feita nem qualquer instituições auluer prejuízo à valia do testemunho na comparação lamstralianas em prol da to temunho oferecido pela mentar em Estados federais.

Conviria obse

tituição federal americana, a Hamílto tratar-se da feitura da Consos governadores nomeados pelo presidente pareceu absurdo fôssem suspensivo sôbre os atos pelo presidente, que teria ainda um veto

Ora, relativamente à assertivaturas estaduais... ( $\left.{ }^{47}\right)$.

parlamentares se enquadram num de que os exemplos de federações tindo-se exista êsse tipo, significaria te federalismo europeu, admipróprias palavras do ilustre relatoria apenas que" "a federação _ nas instituto político uniforme" (48). da Comissão Especial - não é um com a sua eloqüência cheia $\left.{ }^{48}\right)$. Ou como diria João Mangabeira, americana não é o metro de irídio conseria: "a constituição norteda décima-milionésima parte do quarto em Paris, como padrão federação é uma forma de Estado; fôrças, interêsses e objetivos, variávi um sistema de composição de rente e peculiar a cada povo. $\mathrm{Pl}$ la no tempo e no espaço, e ine com as necessidades e os sentimentos de, por isso mesmo, de acôrdo rativo dos Estados Unidos não é tos de cada povo. O regime fedelia. O do Brasil não é nenhum é o do Canadá; nem êste o da Austrácano. $\mathrm{O}$ da Alema e nenhum dêsses, nem o Argentino da AustráRússia" $\left({ }^{49}\right)$.

21-XI-1885, Joaquim Nabuco

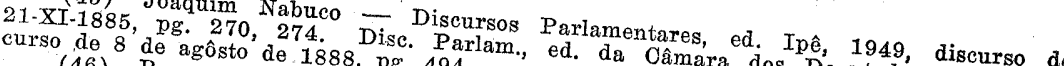

(46) Bryce de 1888, pg. Par. 494

Couve de Murville - op. I, 462 e II, 174, 176 e 177.
(47) W. P. M. Kert., 12,93 e 183

(49) Afonso Arinos - Parecer, 37.
Foi em razão dessas verdades, de resto, intuitivas, que o deputado Afonso Arinos, sustentando o parecer, para ser lógico com suas conclusões, vem a declarar simplesmente que "no Canadá e na Austrália não existe federação" ( ${ }^{50}$ ).

E buscando elucidar o que entendia por regime federativo de tipo brasileiro, apontou como seus pressupostos: a constituição escrita e rígida e a conseqüente supremacia desta sôbre as demais leis, o contraste da constitucionalidade delas pela justiça e o regime presidencial. Não é preciso insistir que incorreu aqui, o jurista ilustre, em palmar petição de principio, dando como demonstrada (pressuposto) exatamente a tese a demonstrar.

Prosseguindo em seu parecer o parlamentar referido apela para a autoridade de Dicey como o autor que teria demonstrado a "incompatibilidade entre o parlamentarismo e a federação de tipo norteamericano e brasileiro" (51).

Dicey, entretanto, se limita a demonstrar a incompatibilidade da federação, que pressupóe - "la suprématie de la Constitution; la distribution des différents pouvoirs du gouvernement entre des corps différents investis d'une autorité limitée et coordennée; le droit reconnu aux tribunaux d'interpréter la Constitution" ( ${ }^{52}$ ) com a sistema constitucional inglês e não com o parlamentarismo, com o sistema da onipotência parlamentar, da soberania legislativa ("le seul principe fondamental de la Constitution anglaise est la souveraineté législative absolue, le despotisme du Roi en Parlement") ( ${ }^{63}$ ), com aquêle particular sistema constitucional flutuante que ignora uma constituição rígida, formal e pràticamente superior às demais leis.

Assim: "La souveraineté du Parlement est (à un point de vue légal) le caractère dominant de nos institutions politiques.

"Le principe de la souveraineté parlementaire signifie, ni plus ni moins, que le Parlement ainsi défini (le mot Parlement signifie, dans la bouche d'un jurisconsulte, le Roi, la Chambre des Lords et la Chambre des Communes) a, d'après la Constitution anglaise, de droit de faire ou de ne pas faire une loi quelconque; il signifie, de plus, que la loi anglaise ne reconnait à aucun homme, ni à aucun corps, le droit de négliger ou d'écarter les lois faites par le Parlement" (54). (50) Afonso Arinos - Discurso pronunciado em 23 de junho de 1950 e publi-
cado no Diário do Congresso Nacional, de 27 de junho de 1950 , pgs. 4909 e 4910 .

(51) Afonso Arinos - Pareer, 37. "Emenda Parlamentarista", avulso da Câmaara dos Deputados, pgs. 48 a 52 , cabalmente refuta a proposicãa formulada.

cf. Soriano de Souza. Direito Público e Constitucional, 1893. pg. 112.
cf. a Introducão (2) de Emelyn C. S. Wade à 9.a ed. inglesa da obra de Dicer, cf. a Introducão (2) de Emelyn C. S. Wade à 9.a ed, inglesa da obra de Dicey,
"Introduction to the Study of the Law of the Constitution", London, 1950, pgs. LIII e segs. $(52)$ Dicey - op. cit., 127 , cf. 146.

(53) Dicey - op. cit., 128. V. Wade and Godfrey Phillips, op. cit., pg. 417 
"La souveraineté parlementaire est donc un fait légal indubitable. Elle est complète aussi bien au point de vue positif qu'au point de vue négatif. Le Parlement peut légalment légiférer en toute matière que le Parlement estime être sujet convenable de législation. D'après la Constitution anglaise, il n'existe aucun pouvoir qui puisse se poser en rival de la souveraineté législative du Parlement" (55).

Noutro passo já dissera: "De Lolme a résume le sujet en une expression triviale que est devenue presque proverbiale: "C'est un principe fondamental, pour les jurisconsultes anglais, que le Parlement peut tout faire, sauf changer une femme en homme et un homme en femme" $\left.{ }^{56}\right)$.

Ao contrário, o insigne constitucionalista inglês reconhece de modo explícito a possibilidade do parlamentarismo ser praticado em Estados de constituições escritas e rígidas ( ${ }^{57}$ ), assim como não silencia que o Canadá (ao tempo a Austrália não era federação) se modelou aproveitando a experiência americana no tocante à forma de Estado e a britânica relativamente ao sistema de govêrno ( ${ }^{(\tilde{8})}$.

Mas para o professor Afonso Arinos o ponto crucial do problema não está pròpriamente na federação, porém no fato da "emenda n. 4 não alterar em nada o Poder Judiciário, previsto na Constituição vigente, como também em nada restringir as suás atribuições, deixando íntegras, inclusive as de natureza política, tal como a importantíssima atribuição de exercer o contrôle da constitucionalidade das leis", e isso porque "o regime parlamentar não aceita o contrôle porque, no fundo e na verdade, não aceita a superioridade efetiva da Constituição sôbre as demais leis" (59).

Destarte, o professor ilustre emburilha a onipotência parlamentar, a soberania legislativa, próprias do sistema constitucional inglês, com o govêrno de gabinete.

"Nessas condições, quer-nos parecer - enuncia o relator - que a emenda estabeleceu, no que concerne ao funcionamento dos poderes uma contradição insolúvel, que é a incoercível predominância do legislativo, no regime parlamentar, predominância que corresponde à falta de supremacia da Constituição, coexistindo com a soberania funcional do Judiciário, peculiar ao presidencialismo federalista, e que decorre da obediência efetiva à Constituição federal" $\left({ }^{60}\right)$.

E mais adiante: "para nós a contradição - parlamentarismo e judiciarismo político - eqüivale a esta outra contradição - supremacia da Constituição e supremacia da lei ordinária e decorrem am-

\footnotetext{
(55) Dicey - op. cit., $63,64$.
(56) Dicey = op.cit., 38.
(57) Dicey = op. cit., 139.

(58) Dicey - op. cit., 129. 147 nota $1_{1}$ it sob no 27

(58) Dice - Arinos. - Part., 122 e 147,
(60) A. Arinos - Parecer cit., 44.
(60)
}

bas da contradição parlamentarismo e federação", ( $\left.{ }^{61}\right)$ idela que vol-

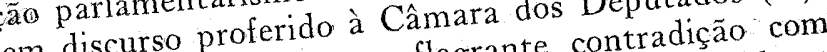
em flagrante contradiçavidente No mesmo parecer, entretanto do refido discurso, procedência, escrevera o professor Ẩre as leis ordinarias é assunto "a supremacia da Constituiça Govêrno. Podem admitir está superque independe dos sistemas de Gón unitários ou federais, monal

legalidade constitucional os pars ou presidencialistas ( legalicanos, parlamentaristas ou presidencialist da constit

De resto, o fundamento do contraste da cederalista". leis não reside no "presidencialis declaração de inconstitucionarior em

O fundamento racional da é a existência de uma lei superior em. de atos legislativos e executivos é a exister

formalmente diversa das leis

A

A existencia dia a sua reforma uma tramia norma de outra ordinárias, que fâsse assim e não se diferençaria.

especial. Ne elas se estabelecer uma hicunerior, soberana, irreformável para entre elas se estabé uma lei superior, soberana, irela com os

"Ou a Constituição é uma Ruy Barbosa, ou se nivela com da lepor meios comuns, argumentava êstes, é reformável ao sâbor da le- como êal, en atos de legislação usual, e, como êstes, échgislatura" (64). distinção com clareza matemática: “ituir a si

Ruy estabeleceu a distinção com soberana de se consitude exetituição é o ato da naça do legislador em atitude secundán próprios pomesma. A lei é o ato do legrtituição demarca os seus pro A Consmesma Constituição. A Constituiçados pela Constituiçáo. A Conscutar a Constitucos poderes conlina, A lei, deres. A lel tem do povo no exercício do pricão. A Constituição é tituição é criatura do pono órgão da Constitulção. A Constitu Estado. criatura do legislador como outorgado aos vários podes do leres insinstrumento do mandato outorganal por um dos seus poderes insA lei, o uso do mandato constitur

tituídos na Constituição". ( ${ }^{5}$. . es que antes de se federalizarem, as Foi por possuirem tais noçoes que antes da constitucionalidade colônias americ das leis $\left.{ }^{66}\right)$. (61) Afonso Arimos

(62) Afonso Arinos - Discurso de
1 (TII-50, pg. 5035 . 41. (63) Afonso Arinos - Parecer inconstitucionais, 44. do Direito Administo barbosa. Atos introduea ao estudo do cf. RuY Cirne Lima - Federal Brasileira, coligidos e ord

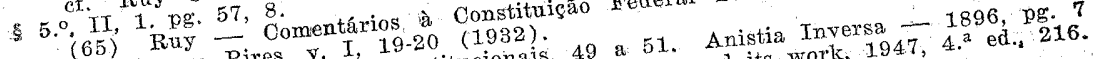

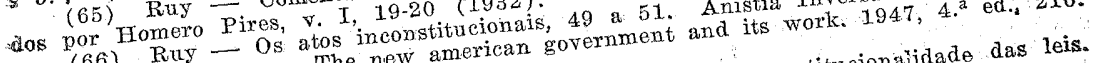
James T. Young - The new american government a constitucionaidade Dicey - op. eit., 146. De resto, o Estado unate Comentários à Cons 
Assim, melhor se diria que êsse contraste em vez de derivar das. que nêles há necessidade prática se pratica nos Estados federais, porra das competências distribuída de uma constituição rígida definidoestatal $\left({ }^{67}\right)$.

Em regra, e não como conseqüîn. ma da constitucionalidade das leis dera forçada, $\left({ }^{68}\right)$ surge o probleda supremacia constitucional.

A conseqüência é

nem sempre extraida e usada não resta dúvida, no plano lógico, mas rígidas.

$\mathrm{Na}$ Suica o

nais $\left({ }^{69}\right)$. De resto, a solução poditucional das leis se reduz às cantoseja a mais feliz.

Relativamente

rigir abusos 'de poderes e competên desfazer disputas entre, e corduais, Gettell advertia: "in some federatias entidades federal e estaand Germany, the constitution some federations, such as Switzerland the national legislature, whose placed under the guardianship of between the central and local authorities final in case of disputes supremacy exists. In others authorities. In these states legislative extent Autris. In others, such as the United States, and gislative federations, the highest national and some of the Latin-American mantain the constiutional balanceurt decides disputes in order to

$\underset{\text { mass }}{(67)} \mathrm{R}$

ma associacão de sociedades, como são mentos relativamente autôn políticos de legislaçấo e acẽorativos, a distribuicão que, nutrit essencial do que nas Constituicõose o compóem, constitui uma ne nacional e nos ele56: "convém notar que esta doutrina a autoridade política é unificada", ainda mais:

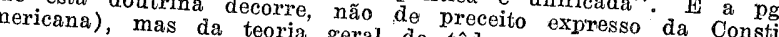

Dicey - op. cit., 127, 146.

titution marks out a cit. 363, 4. "In the federal system of government where the of to keeps within its states or provinces, it is necessary that government and another for existence of the federal system would bet settle conflicts of authorityl compel each powers gislature determines the distinction between constitution to keep within its constitutional

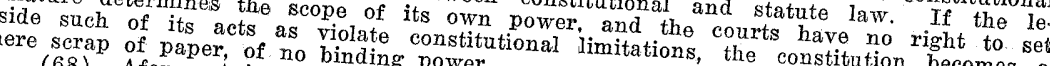
(68) Afonso Arinos - Parecer eit., 41.

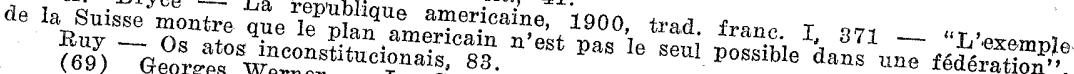
ples, 36 e 111 contre la pluissance public, in "Suisse"gime politique e Roger Secretan.

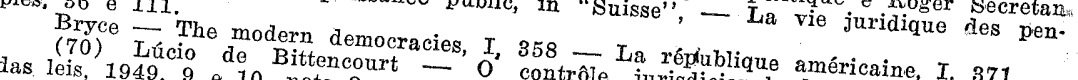
Pinto Ferreira 10 , nota 2 . do o \& 8 pgs. 101 a 124 . Principios gerais do Direito Constitucional Moderno, 1948, to

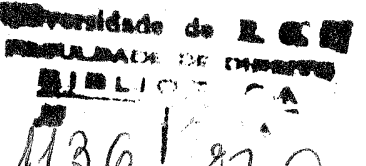

local governments. In these states judicial supremacy exists" $\left({ }^{71}\right)$.

De outro lado, Estados não federativos, com governos não presidencialistas, também conhecem a fiscalização judiciária das leis ( 72 ), e as federações parlamentares do Canadá e da Austrália a praticam.

Dicey já proclamara: "au Canadá, comme aux Etats-Unis, les tribunaux deviennent innévitablement les interprêtes de la Constitution" $\left({ }^{73}\right)$.

E Couve de Murville confirma: "l'autorité judiciaire possède en outre un pouvoir qui n'appartient pas aux tribunaux du RoyaumeUni. Les tribunaux des Dominions doivent juger si les Actes du Parlement du Dominion ne dépassent pas les pouvoirs constitutionnels du Parlement, et même les lois conforme à la constitution du Dominion ne sont pas incompatibles avec un loi impériale, aplicable à ce Dominion" ( $\left({ }^{74}\right)$.

Sustentando perante a Câmara o seu parecer, o prof. Afonso Arinos citava Ruy afirmando não se encontraria "jamais na obra dêsse grande jurista qualquer opinião que supusesse seu assentimento à coerência ou a concomitância dêsses dois institutos fundamentalmente antagônicos, que são: de um lado o regime político parlamentar e, de outro, a permanência do contrôle judiciário da constitucionalidade das leis. Esta é a antinomia fundamental, a contradição intrínseca, que não é puramente formal, mas substancial..."

“A afirmação de Rui é categórica. Não concebe a possibilidade da legalidade das leis pelo Poder Judiciário, a não ser no regime federal subordinado ao sistema presidencial" ( ${ }^{75}$ ).

$O$ engano do parlamentar também aqui é evidente e palpável.

Ruy, num dos seus grandes discursos ao Senado, sentenciava: "na Europa, entre os países mais adiantados, se ambiciona a criação de um grande tribunal como êste, destinado a conhecer dos atos dos outros dois poderes políticos, mesmo quando se trata de países sob o regime parlamentar, o que quer dizer, onde existe responsabilidade para o govêrno" (76).

Antes de derivar o contraste judicial como louvável peculiadade do presidencialismo, advertiu Ruy Barbosa, em parecer notável: "nenhum sistema de govêrno precisa tanto da justiça como êste.

(71) Getell op. cit., 230, 231.

v. Const. portuguêsa de 21 de do Amazonas, I, 82 (nota). E' o caso da No. Marnoco e Souza - Direito Politico, Coimbra, 1910, n. ${ }^{\circ} 323$, pgs. 781 a 78

(74) Couve de Murville - op. cit., 19. Wade and Godfrey Phillips, op. cit.. pg. 417 . ) Afonso Arinos - Diário do Congresso Nacional, de 1-VII-50, 5035.

já nos "Atos inconstitucionais" Ruy dava ciência do que sôbre o assunto se pensavà,

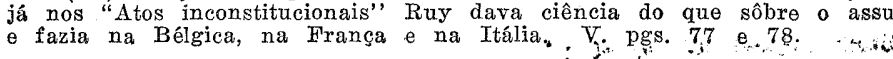

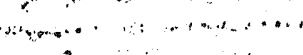


Ela é o elemento preservador e a ultima ratio dêste regime. Anulá-la fôra destruí-lo" (77),

E já nos "Atos Inconstitucionais" ensinava o sumo jurisconsulto: "nas colônias parlamentares da Inglaterra essa regra é geral (a de que os juízes recusarão aplicar leis inconstitucionais). Essa jurisdi"ção coloca os tribunais canadenses e os das outras dependências inglêsas, parlamentarmente constituídas, numa situação semelhante à das justiças dos Estados Unidos, acima, como estas, do poder legislativo, quanto à interpretação das leis" $\left.{ }^{78}\right)$.

E em França, informa Paul Duez, "un vigoureux effort en faveur du controle jurisdictionnel de la constitutionnalité des lois a été reffectué ces dernières années par la doctrine française. Parmi les maitres du droit public, ils sont de plus en plus nombreux ceux qui, non seulement voient l'institution avec grande sympathie, mais estiment même qu'elle a dejà pénetré le droit positif français" (

Em verdade, não pode haver conflito entre a faculdade, ou o dever, dos tribunais negarem aplicação à leis ou decretos, desde que os entendam contraventores da Constituição, e a atribuição da Câmara de negar apoio a um govêrno, forçando-o a demitir-se.

A intervenção dos tribunais se deve à iniciativa das partes que dela imediatamente se beneficiam. E' in casu, vincula apenas os litigantes.

"A justiça não examina teses, ensinava Ruy Barbosa, com a sua autoridade proverbial. A justiça não sentenceia teorias. A justiça não vota princípios abstratos. A justiça não revoga leis.

"Cada um dêsses problemas de interpretação tem de revestir a forma de um litígio, circunscrito a um caso individual; e sôbre êste é que o julgador se pronuncia" $\left.{ }^{80}\right)$.

Ora, a responsabilidade política do gabinete perante a Câmara é apurada mediante critérios evidentemente políticos, de conveniência e oportunidade e não de estrita legalidade.

H. Berthélemy elucida perfeitamente: "cette responsabilité est dite politique parce qu'elle n'implique aucune infraction, aucune faute de la parte du gouvernement, mais un simple désacord avec les chambres" ( $\left.{ }^{81}\right)$.

(77) Ruy Barbosa - O Impeachment na Constituição da Bahia, "Direito", v. (78) Ruy Barbosa - Os atos inconstitucionais, 82 , onde refere

overnment in the British Colonies. (1880), pags. 219, 20

Munro - The Constitution of Canadá (Canbridge, 1889), pgs. 11 e 12

Bourinot - Canadian studiẹs on comparative politics (Montréal, 1890), pg. 24. Moses - The Federal Govern. of Switzerland; pg. 146 e segs.

(79) Paut Duez - Le contrồe jurisdictionnel de la constitutionnalité des leis

en France, in "Mélanges Maurice Hauriou", 1929, pg. 21.3.

(80) Ruy - O Direito do Amazonas, 'I, 94. Atos inconstitucionais, 102, 3
E Burdeau: "cette responsabilité peut être mise en jeu à raison De ministre dans l'exercise de ses atribude tout acte a même que l'acte serait parfaitement légal" $\left.{ }^{82}\right)$.

Ora, já advertia Ruy Barbosa: "a regra universal da justiça é entenciar o direito controverso, e não pronunciar sôbre a convenisentencia ocasião, ou o merecimento das partes. "Courts have nothing ência da ocasiao, ou of expediency". Nada têm os tribunais com as questões de utilidade. Das questões de utilidade quem decide é a autoridade política" $\left.{ }^{83}\right)$.

Aliás, é cânon de hermenêutica que os tribunais ao julgarem os Alás, calade ou não de um estatuto se absterão de questionar casos de validade ou não de um estatuto se o legislador tinha poder dos motivos políticos impertinente à decisão a justiça, conveniênpara fazer a lei, sendo impertinentativo ou administrativo ( ${ }^{(84)}$

Com efeito, inexiste a antinomia apontada entre o parlamentarismo e a função judicial de custodiar a Constituição. São soluções distintas, que se situam em planos diversos, com motivações diferentes e finalidades peculiares, incapazes de se chocarem e muito menos de se excluírem.

São as razões por que tenho como compatível o sistema parlamentar de govêrno com a forma federativa de Estado, também em mosso país e à luz do nosso direito constitucional.

Pôrto Alegre, 10 de agôstọ de 1950.

(82) G. Burdeau - op. cit 103.

(83) Ruy W. W Direito do Amazonas, II, 593 . Constitutional Law of the United States, 1925 , pg. 30,1 - "with the motives of lisislate being concede, the wisdom or cern themselves. The power of congest is exercised is held to be beyond judicia criticism or control. H. C. Black - Handbook of the Construction and Interpretation of the 1896, pg. 27.
Charles Evans Hughes - The Supreme Court of the United States. Trad. esp. 1946, pg. 52: "Los tribunales consideran, que, el depositário de la sabiduría. Mientras

actúa dentro de lis limites del po 


\section{RELATÓRIO E PARECER}

\section{Relator: PROF. FAY DE AZEVEDO}

Discute o bacharel Paulo Brossard de Souza Pinto, em trabalho apresentado a êste Congresso, a questão Souza Pinto, em trabalho tema parlamentar de govêrno com a fão da compatibilidade do sisquer genèricamente, em têrmos de teoria forma federativa de Estado, em face do nosso direito positivo teoria estatal, quer especificamente,

Comeca por situar positivo.

mando haver a mesma surgido entré no tempo e no espaço, afirquando já havia quem sustentasse nós no dealbar do novo regime, federação e parlamentarismo, de emenda n. ${ }^{\circ} 4$ à Constituicão da reeditada em oposição ao projeto Citando Ruy Barbtituição da República.

sen, Bonnard, Nézard, Laferrière, Gsmein, Redslob, Burdeau, Kelcisco Campos e Ruy Cirne Lima, precisa Vedel, Darcy Azambuja, Franfastável distinção existente entre frecisa o A., numa síntese feliz, a inavêrno e sistemas políticos, com suas motivastado, formas de goliares, para mostrar que , com suas motivações e finalidades pecucessàriamente, podr umas não implicam ou excluem oues pecucom governos parlamentares, diretoriastados unitários ou federais: realmente, não se verifica uma relacão ou presidenciais. E' que, Estado e sistemas de e a limitações impostas aos poderes prendendo-se ao relacionamento à centralização ou das poderes legislativo e executivo; aquelas,

Faz o A. uma análise subacão política.

govêrno e da forma federativa de face da doutrina e do direito compstado para, estudando-os em da tese enunciada, inclusive comparado, concluir pela procedência do nosso direito, inclusive quando encarada particularmente ì luz contra ela rais entre o Senado Federal e a Câmara eqüivalência de poderes getrôle da constitucionalidade e a Câmara dos Deputados, e ao con-

Astado alegada incompatibilidade entre o govêrno parlamentar e

E' uma afirma resiste à controvérsia doutrinária.

Que essencializa o destituída de base.

Iho de ministros, dependente da confianc $E^{\prime}$ o govêrno de um conserefletir a opinião pública. Oue confiança do parlamento, que deve existência de um govêrno aue obsta, numa federação de Estados, a
Porventura, num Estado federal o Congresso não é, talqualmente num Estado unitário, um dos órgãos da soberania nacional? E, se legisla e exercita as suas demais atribuições para tôda a nação, que o impede de delegar a um gabinete a função executiva?

São perguntas que permanecem irrespondidas pelos impugnadores da tese em discussão. Êstes se apegam a argumentos especiosos, nugas e sutilezas, na vã tentativa de refutá-la.

O que há de curioso em tudo isso - cabe assinalar - são as demasias e exaltações dêsse afêrro acadêmico a formas de govêrno, extremando-se em recursos e artifícios de dialética, quando sabido é que, se de algum modo pode influir a modalidade de exercício do poder público nos destinos dos povos, o que, no entanto, tem caráter decisivo é a substância humana e o teor econômico-social dos Estados que Ihes dirigem a evolução.

Sílvio Romero, em seu ensaio "Parlamentarismo e presidencialismo na República do Brasil", imaginou uma interrogação que, de fato, formularia a objeção capital à tese da compatibilidade do govêrno parlamentar com o Estado federal: "Como poderá um ministro responder por fatos ocorridos nos Estados, que são autônomos?" Deverá responder sòmente pelos fatos que, embora ocorridos nos Estados, se vincularem à competência do govêrno federal. Eis a solução que, em sua simplicidade, inutiliza tôda a argumentação dos adversários do parlamentarismo, nesse sentido. E' claro que será necessária uma rigorosa discriminação entre as órbitas de ação dos governos federal e estadual. Mas essa delimitação é igualmente indispensável no sistema presidencial de govêrno. Não se exige, portanto, coisa diversa do que estabelece a Constituição de 46, como faziam as anteriores Constituições republicanas.

A questão fundamental, na matéria, liga-se à inelutável distinção que importa fazer quanto a estrutura, fins ou modalidades de exercício do poder estatal. Poderá estabelecer-se - é certo - uma correlação, mais ou menos estreita, entre os fins do poder estatal e a maneira como seja exercido. Para designar a forma do poder estatal, encarada sob êsses dois aspectos solidários, poderá usar-se a expressão "regime político". O que, porém, não se pode confundir é "regime político" com "forma de Estado". Porque esta diz respeito à natureza interna do poder estatal, à sua contextura, à sua estruturação. A "forma de Estado" na realidade não se correlaciona com a "forma de govêrno". Uma e outra não se ligam necessàriamente.

O A. cita os sugestivos exemplos que o direito comparado oferece, na atualidade como no passado "da conjugação num mesmo Estado, do parlamentarismo e da federação, do mesmo modo que, em outros, desta com o sistema presidencial": Canadá, Austrália, Alemanha, Áustria. 
Não seria, aliás, novidade doutrinária, mesmo em nosso país, império, uma ala do Partido Liberal lano e o federalismo, Em pleno alvores das instituições monárquicas e do a idéia da federação sem alvores da República, o Particicas e do govêrno parlamentar sem Rio Grande do Sul, do Partido Libederalista, que se originara, no grande tribuno Silveira Martins, Liberal e, como êste, sob a chefia no "a revisão da Constitu Martins, inscreveu, no n. ${ }^{\circ} 2$, sob a chefia do tiva. de acôrdo Constituição Federal para mo n. ${ }^{\circ} 2$ do seu programa, na generalidade com os princípios de govêrno parla república federa.

Por igual improcedentes do sistema de govêrno parlamentar no Brasil, que, contra a adoção fundamental caracterís da Constituição Federal, segundo arrimar-se dade de reprearenterística da federação brasileira, segundo os quais. a petência epresentação dos Estados no Senadlo e derivando da "igual o sistema parlam dois ramos legislativos, salvo da igualdade de como sistema parlamentar importaria "em abolvo os casos específicos", deres gerais entre o Senado e a Câmara", im a eqüivalência de po representação igual dos Estados no Senad; importaria "em anular a O argumento aos da Câmara dos Deputados". exercício de po-

inconsistente como os demais, na disar à primeira vista, mas é tão convincentemente, demonstrando que não da matéria. O A. refuta-o atribuições entre o Senado e a Câmara não se trata de identidade de ral, tendo cada uma das casas em âmara, mas de eqüivalência em dé prerrogativas específicas, de em que se divide o Congresso $\mathrm{Nac}$ gemais uma especificas, de sorte que "ao seu número so Naciona ponsáveis em favor da Câmara, se sòmente perante

Ministros".

de Science Politique" citar a clara lição de Georges Burdeau (Trate Etats fédéraux actuellement 1950, t. II, ps. 430-31). "Dans ("Traité bres sont aux actuellement existants les pouve qu'a cond sensiblemente égaux en ce sens quveirs des deux Chamqu'à condition d'être voté par toutes dens qu'une loi n'est parfaite Canadá (artic (art. 51), Argentine (art. 36), Etats-Unis (art. I, sect. (art. 37 38,39 ), Yfrique du Sud (art. 19), Suénézuela (art. 81), (art. 37, 38, 39), Yougoslavie (art. 57) 19), Suisse (art. 89), U.R.S.S. membres à l'exercice de la puisance fédéra participation des Etatsleur accord est nécessaire pour que fédérale est donc assurée puisque ou l'autre des aécessaire pour que la loi puisse naitre puisque la priorité dans la discussouisse de privilèges particuliers tue l'une Chambre basse ou la possibilité desojets financiers réservée à de justice accordée à la Chambre des Etats ce sont lá des dispositions que l'on rencontre également dans les Etats unitaires e qui ne changent rien à l'égalité de principe entre les deux éléments dhe Parlement." O ilustre professor da Universidade de Dijon cita ainda, em nota infratexto, o Brasil "d'après la constitution de 1891". Poderia fazê-lo também "d'après la constitution de 1946", se notícia do nosso último código político já houvesse chegado à França para constar de uma edição de 1950 ...

$\mathrm{Na}$ mesma ordem de idéias, diz-se que, sob a égide do parlamentarismo, dependendo o executivo do voto da maioria dós deputados, poderia verificar-se o predomínio dos grandes Estados, através de suas bancadas, mais numerosas, o que seria lesivo ao equilíbrio. federativo. A objeção, todavia, esbarra em possibilidade idêntica, argüível ao presidencialismo, através da eleição do presidente da República. Pode ocorrer que a escolha do primeiro mandatário do. povo seja conchavada entre grandes Estados e imposta à nação, ou. que se processe a mesma tendo em vista a base eleitoral fornecida por uma populosa unidade da federação. A concretização da primeira hipótese, como ninguém ignora, foi mesmo apontada como um dos vícios de que se ressentia a prática do regime, sob a Primeira República.

Em verdade, para enfrentar tal risco outra é a terapêutica aconselhável: a integral conversão em realidade do papel atribuído aos partidos políticos no funcionamento das instituições. A existência de partidos verdadeiramente nacionais, de objetivo e de espírito. verdadeiramente nacionais, sobranceiros a injunçôes de cunho regionalista, liquidará com o risco aludido, talvez mais temível, aliás, no presidencialismo do que no parlamentarismo.

$$
\text { * * * }
$$

Tampouco aceitável é a objeção consistente em que o parlamentarismo feriria o princípio da supremacia da Constiuição e do contrôle da constitucionalidade das leis pelo Judiciário. Tal princípio, como demonstra o A., não decorre do presidencialismo, nada impedindo que também o consagre o parlamentarismo. Exatamentecomo, embora sendo êle imprescindível no Estado federal, nada obsta que por igual o adote um Estado unitário.

Relacionar o sistema parlamentar de govêrno com a ausência de supremacia da Constituicãa e de contrôle judiciário da constitucionalidade das leis eqüivale a confundir $\mathrm{o}$ parlamentarismo com o sistema constitucional inglês - êrro tão crasso quanto o de confundir o presidencialismo com o sistema constitucional dos Estados Unidos. Uma forma de Govêrno, como uma forma de Estado, pode 
prias, mas varia a um tipo genérico, com características essenciais prónacionais e da incoercívol e no espaço, em função de peculiaridades

$$
\text { * ** }
$$

Somos de parecer, pelas razões expostas, que seja aprovada broposição proficientemente justificada pelo A., em brilhante balho, o sistema parlamentar de govêrno é A., em brilhante trafederativa de Estado, seja à de govêrno é compativel com a forma nal dos novos, seja em face do direito positio prática constitucio-

Sala das Sessões, 15 de agôsto de 1950

$$
\begin{aligned}
& \text { Camillo Martins Costa - Presidente } \\
& \text { Fay de Azevedo - Relator } \\
& \text { Darcy Azambuja } \\
& \text { João Abreu } \\
& \text { Francisco Juruena } \\
& \text { Francisco Machado Vila }
\end{aligned}
$$

\section{APRESENTAÇÃO EM PLENÁRIO}

O SR. PRESIDENTE - Júlio César Bonazzola - Vamos traMENTARISMO ponto da Ordem do Dia: FEDERAÇÃO E PARLAde govêrno com a forma compatibilidade do sistema parlamentar Dr. Paulo Brossard de Souza Pinto de Estado, tese de autoria do de Azevedo, a quem celator o Dr. Armando Fay O SR FAY concedo a palavra.

tas, minhas senhoras e meus $O$ parecer que tive a honrares.

das satisfações, subscrito por figura emitir, vi, com a mais justificada rídicas, limitando-me a mencionar eminentes das nossas letras jutros nomes também a mencionar dentre êles, para não citar juAzambuja e o eminente advogado e jurisão, o ilustre professor Darcy Avêsso a elogiar, creio que o que se a que de início aludia, exprime que se contém no remate do parecer juízo fiel do valor do trabalhom exatidão, traduz com segurança um o parecer, e ao propor que seja apresentado. Eu digo, ao terminar a tese, que se trata de um a provada a proposição que condensa temente, quer dizer, com trabalho brilhante, redigido proficienidade, destreza de argumentarimento completo do assunto, habi-

Discute o bacharel Paulação e brilho de forma. apresentado a êste congresso, a questão de Sousa Pinto, no trabalho tema parlamentar de govêrno com a forma federativa de Estado, quer genèricamente, em têrmos de teoria estatal, quer especificamente, em face de nosso direito positivo.

\section{(LÊ O RELATÓRIO E PARECER)}

O SR. PRESIDENTE - Está aberta a discussão sôbre a tese que acaba de ser comentada pelo sr. professor. Se não houver observações, votaremos separadamente, em primeiro lugar, por razões de ordem e de forma unitária, a primeira tese, da "Incompatibilidade "do sistema parlamentar de govêrno com a forma federativa do Estado."

Diz o relatório - “Somos de parecer, pelas razões citadas que se aprove a tese proficientemente justificada pelo brilhante trabalho do dr. Paulo Brossard de Souza Pinto. O sistema parlamentar de govêrno é compatível com a forma federativa do Estado, à luz da doutrina e das práticas constitucionais dos povos e também em razão do direito positivo brasileiro."

Peço desculpas ao plenário, pela minha tradução arrevezada. Os srs. congressistas que estiverem conformes com o parecer, mantenham-se sentados como sinal de aprovação. (Pausa)

Está aprovada a tese.

(Votou contra o sr. José Luiz Martins Costa)

O SR. BRUNO DE MENDONÇA LIMA - Peço a palavra, sr. Presidente.

O SR. PRESIDENTE - Tem a palavra o ilustre congressista.

O SR. BRUNO DE MENDONÇA LIMA - O meu voto, sr. Presidente, é no sentido de que o direito positivo brasileiro não permite o regime parlamentar.

O SR. JOSÉ LUIZ MARTINS COSTA - Peço a palavra, sr. Presidente.

O SR. PRESIDENTE - Tem a palavra o ilustre congressista.

O SR. JOSÉ LUTZ MARTINS COSTA - Subscrevo o voto do Hustre professor, Bruno de Mendonça Lima.

O SR. VICTOR RUSSOMANO - Peço a palavra, sr. Presidente.

O SR. PRESIDENTE - Tem a palavra o ilustre congressista.

O SR. VICTOR RUSSOMANO - Sr. Presidente. Parece-me que não há esta pretendida incompatibilidade dentro do sistema federativo brasileiro. $\mathrm{Na}$ crítica feita, a suposta incompatibilidade é a de que o sistema parlamentar de govêrno requer uma centralização que é incompatível, esta sim, com a federação e autonomia dos Estados. Neste sentido é que aprovo o brilhante trabalho do distinto colega autor da tese, que se mostra um erudito e um apaixonado pelo sistema parlamentar.

18 - R. D. - $2 .^{\circ}$ Vol. 
$\odot$ SR. ALCIDES DE MENDONÇA LIMA - Peço a palavra, sr. Presidente.

O SR. PRESIDENTE - Tem a palavra o ilustre congressista.

O SR. ALCIDES DE MENDONÇA LIMA - Sr. Presidente. Aceitando o ponto de vista do professor Bruno de Mendonça Lima, quero manifestar que entendo ser teòricamente compatível o sistema federativo com o parlamentarismo. Entretanto, quero ressaltar a minha adesão intransigente ao sistema presidencialista, para não parecer que o meu voto à parte teórica pudesse fazer periclitar a minha vocação presidencialista.

O SR. GIRÃO BARROSO - Peço a palavra, sr. Presidente.

O SR. PRESIDENTE - Tem a palavra o ilustre congressista.

O SR. GIRÃO BARROSO - Voto, sr. Presidente, no mesmo sentido.

O SR. HENRIQUE RUPP JÚNIOR - Peço a palavra, sr. Presidente.

O SR. PRESIDENTE - Tem a palavra o nobre congressista:

O SR. HENRIQUE RUPP JÚNIOR - Meu voto também é no mesmo sentido.

O SR. PAULO BROSSARD DE SOUZA PINTO - Peço a palavra, sr. Presidente.

O SR. PRESIDENTE - Tem a palavra o nobre congressista.

O SR. PAULO BROSSARD DE SOUZA PINTO - Pedí a palavra, sr. Presidente, apenas para um esclarecimento, uma vez que já está a matéria votada.

Quero que fique bem claro que não é objeto da minha tese, nem é das suas conclusões, decidir da conveniência ou inconveniência de um ou de outro sistema de govêrno, mas apenas estudar a possibilidade, à luz do direito positivo brasileiro, da adoção de um sistema de govêrno em determinada forma de Estado.

Apenas isto.

O SR. PRESIDENTE - Está aprovada a tese, com os votos em contrário anotados pela Secretaria e com as restrições que acabam de ser formuladas.

O SR. ARMANDO FAY DE AZEVEDO - Peço a palavra, sr. Presidente, apenas para levantar uma questão de ordem.

O SR. PRESIDENTE - Tem a palavra o nobre congressista.

O SR. ARMANDO FAY DE AZEVEDO - Como V. Excia., sr. Presidente, declarou que a tese havia sido aprovada com restricões, pergunto-lhe se essas restriçoes não devem ser tomadas como declarações de voto e tão sòmente assim, de modo a não implicar em quaisquer restrições ao conteúdo da tese, que, estaria, então, aprovada integralmente.

O SR. PRESIDENTE - Perfeitamente, a tese foi aprovada na íntegra.

\section{A REVIISÃO DAS LEIS ORGÂNICAS MUNICIPAIS PELA ASSEMBLÉTA LEGISLATIVA}

\author{
Arno Schilling
}

1 - Atualidade do tema. 2 - Desdobramento das questões. 3 Conceito de autonomia política. 4 - A autonomia municipal na Conceito de au 1891.5 - Nas Constituições de 1934. e 1946. 6 - O regime municipal na Argentina. 7 - Um acórdão recente do Supremo Tribunal Federal sôbre imunidades de vereadores. 8 - O Munićpio ñ̃o está para o Estado, como êste para a União. 9 - Constitucionalidade do regime de carta própria. 10 - A feitura da Lei Ortucionalidado constitui exercício de poder regulamentar. Distingânica municipal constitui exercicio de poder 11 A feitura cão entre poder legislativo e poder executivo. 11 - A feitura da Lei Orgânica Municipal resulta do exercício de uma competência, não Orgânica Municipa, mas transferida pelo Estado. 12 - O Município, como audelegada, mas transferida pelo Estado. Estado. 13 - A independêntarquia administrativa, e o contrôle do Estado. 13 independência do cia e harmonia dos poderes. 14 - Significação da independencia do Poder Judiciário. 15 - Análise do ato de revisão e sua justificaPoder Judiciário. 15 - Inconstitucionalidade do Estatuto político do Estado de São Paulo 17 - Constitucionalidade da revisão das leis orgânicas municipais. 18 - Conclusões.

- Tema de ardente atualidade é o que diz com a faculdade, que se arroga a Assembléía legislativa do Estado, de revisar as Leis Orgânicas dos Municípios; faculdade assentada na Constituição do Estado, em preceito que atribui ao órgão legislativo estadual ção do Estado, empetência exclusiva de rever as leis orgânicas municipais, a-fimde expurgá-las de disposições contrárias à legislação

tadual (Constituição do Estado - art. 46, XVIII)

Qualificando-a de exclusiva, a lei magna do Estado determina Qualificando-a de exclusiva, a ei menda de colaboração do Poque o exercício dessa competência independa degislativo não necessita de sanção, nem é suscetível de veto. 